\title{
Numerical Optimization of Double Tube GHE for Ground Source Heat Pump
}

\author{
Md. Hasan Ali ${ }^{1,2, *}$, Akio Miyara ${ }^{3,4}$, Keishi Kariya ${ }^{3}$ \\ ${ }^{1}$ Graduate School of Science and Engineering, Saga University, Saga, Japan \\ ${ }^{2}$ Department of Energy Science and Engineering, Khulna University of Engineering \& Technology, Khulna, Bangladesh \\ ${ }^{3}$ Department of Mechanical Engineering, Saga University, Saga, Japan \\ ${ }^{4}$ International Institute for Carbon-Neutral Energy Research, Kyushu University, Fukuoka-shi, Japan \\ Email address: \\ mhakuet@yahoo.com (M. H. Ali), miyara@me.saga-u.ac.jp (A. Miyara), kariya@me.saga-u.ac.jp (K. Kariya) \\ ${ }^{*}$ Corresponding author
}

To cite this article:

Md. Hasan Ali, Akio Miyara, Keishi Kariya. Numerical Optimization of Double Tube GHE for Ground Source Heat Pump. International Journal of Sustainable and Green Energy. Vol. 6, No. 5, 2017, pp. 64-75. doi: 10.11648/j.ijrse.20170605.11

Received: July 29, 2017; Accepted: August 7, 2017; Published: August 23, 2017

\begin{abstract}
In this paper, a two-dimensional axisymmetric numerical simulation model was developed for optimization of double (coaxial) tube vertical ground heat exchangers (GHEs) in cooling mode. Details of the heat transfer rates and pressure drops for each model are presented and analyzed. The results of the numerical study of optimization of double tube vertical GHEs have been done by considering heat transfer rates and pressure drops. The effect of different inlet and outlet tube diameters, and mass flow rates were numerically investigated. Effect of the different materials on heat transfer and longtime operation also discussed. The double tube vertical GHEs are more effective in laminar flow condition considering balance between heat transfer and pressure drop. The results indicate that since in laminar flow condition, pressure drop is not significantly high, it is possible to reduce the inlet and outlet diameter of double tube GHEs if double tube GHEs operate in laminar flow condition. The heat transfer rate decreased only $17 \%$ but diameter of the inlet tube can be reduced from $130 \mathrm{~mm}$ to $40 \mathrm{~mm}$ with fixed outlet diameter $20 \mathrm{~mm}$. Heat transfer rate can also be enhanced by reducing the outlet tube diameter for a fixed inlet tube diameter. Long time operation suggested the possibility of installation of multiple double tube GHE at $2.0 \mathrm{~m}$ apart.
\end{abstract}

Keywords: Ground Source Heat Pump, Vertical Ground Heat Exchanger, Double Tube Ground Heat Exchanger, Optimal Design, Numerical Simulation, Heat Exchange Rate, Pressure Drop

\section{Introduction}

Compare to conventional air source heat pumps, the ground source heat pump (GSHP) systems have high efficiency and environmental benefits [1-3]. In recent years, GSHP systems are more attractive in residential and commercial buildings around the world. GSHP uses the ground as a heat source/sink for space heating and cooling as well as domestic hot-water. The ground is warmer than the atmosphere in winter and cooler in summer. Also the ground temperature is almost constant after a certain depth. GSHP system takes this advantage of stable ground temperature for heating in winter season and cooling in summer season. The power consumption of GSHP systems is lower than air source heat pump (ASHP) systems. This energy saving effect can reduce global warming. However, the cost of equipment and installation are important consideration for economical concern.
Though higher initial cost, GSHP systems are the most efficient heating and cooling technology since they use $25 \%$ to $50 \%$ less electricity [2] than other traditional heating and cooling systems. In order to gain an understanding of how well GSHPs function after installation, analysis of their performance needs to be conducted [4]. In a GSHP system, heat exchange between ground soil and working fluid takes place via a closed-loop i.e. ground heat exchanger (GHE) buried in horizontal trenches or vertical boreholes. The vertical GHEs, generally called borehole heat exchangers (BHEs) being a common choice because they required small land area of installation and significantly higher energy performance compared to horizontal systems [5]. To overcome the excess installation cost due to oversize or reduction of energy saving due to under size, optimization of GEHs performance is necessary which will improve the overall performance of GSHP system. The main costs of vertical GHE 
consist of borehole drilling, length and diameter of GHE. Heat transfer analysis of borehole GHE is important to size the GHE which optimizes the performance [6].

Besides of experimental works, many researches are interested to analytical and numerical optimization of GHE performance analysis which helps to improve the thermal performance and economic efficiency of GSHP and GHE design. Analytical and numerical models have been reviewed [6] to investigate BHE's performance. To maximize the thermal performance and minimize the cost, optimization of GHEs is an important objective function. In order to better design of BHEs, Khan [7] numerically optimized different components of a GSHP system. Khalajzadeh et al. [8] analytically investigated the effects of GHE design parameters on heat transfer efficiency. For a given heating and cooling loads, optimization of GSHP system was done by Sanaye and Niroomand [9]. Considering multi-objective optimization design of BHEs, Huang et al. [10] proposed an optimization design strategy to minimize the system cost. Hence there is good opportunity to simulate the GHEs numerically for optimization of performance of GSHP systems. Based on Kelvin's line-source theory, the International Ground-Source Heat Pump Association (IGSHPA) proposed BHE design methods [11]. Zhang et al. [12] presented an optimization design methodology in order to size and design borehole heat exchangers coupled with heat pump units and the optimized design parameters of BHEs. Zhang et al. [13] mathematically modeled borehole GHE to optimize the design for GHEs which is favorable to lower the initial cost of the system. Li et al. [14] developed a new solution to reduce the thermal interference of vertical U-tube GHE and validate their result with experimental data of Florides et al. [15] by using ANSYS Fluent. Jalaluddin and Miyara [16] numerically evaluated the thermal performance and pressure drop of the spiral-tube GHE and compared with that of the U-tube GHE. They concluded that the heat exchange rate and pressure drop are important parameters in design of the GSHP system. Most of all literatures analyzed and optimized vertical GHEs considering heat transfer rate, borehole length, backfill material, fluid flow rate etc. but not considering pressure drop during optimization. Therefore in present study, the authors are interested to optimized the vertical double tube (coaxial) GHE considering heat transfer rate and pressure drop.

The three types: U-tube, double-tube, and multi-tube GHEs were experimentally and numerically tested in the cooling mode under the same conditions $[17,18]$. From previous study of Jalaluddin et al. [17, 18], it is shown that double tube (coaxial) vertical GHE has higher thermal performance than other U-tube and multi-tube vertical GHEs. That's why double tube vertical GHE has considered for optimization. The purpose of the present study is to reduce the size (inlet and outlet diameter) of double tube vertical GHE. Effect of the different materials on heat transfer and longtime operation also discussed. A series of numerical performance tests considering heat exchange rate and pressure drop of double tube vertical GHE models were evaluated and compared to each other. To compare thermal performance of double tube GHEs, fourteen double tube GHEs were modeled with different configurations i.e., different inlet and outlet diameter of GHE tube listed in Table 1

\section{Simulation Modeling of Double Tube Vertical GHE}

\subsection{Configurations of Physical Model}

The numerical models consist of two-dimensional axisymmetric $20 \mathrm{~m}$ long double tube vertical GHE surrounded by $22 \mathrm{~m}$ depth and $6 \mathrm{~m}$ diameter ground soil. The schematic diagram of the double tube GHE model is shown in Fig. 1. The example pattern of mesh of double tube GHE and ground soil is shown in Fig. 2. The meshes consist of the working fluid water, GHE tubes and the ground soil. For all of the models, the thickness of annular inlet (outer) stainless steel (SS) tube and circular outlet (inner) polyvinyl chloride (PVC) tube were $5 \mathrm{~mm}$ and $4 \mathrm{~mm}$ respectively. Due to the axisymmetric of the problem domains, only half of the working fluid, GHE tube, and the ground soil were modeled in $2 \mathrm{D}$ to reduce the computational effort.

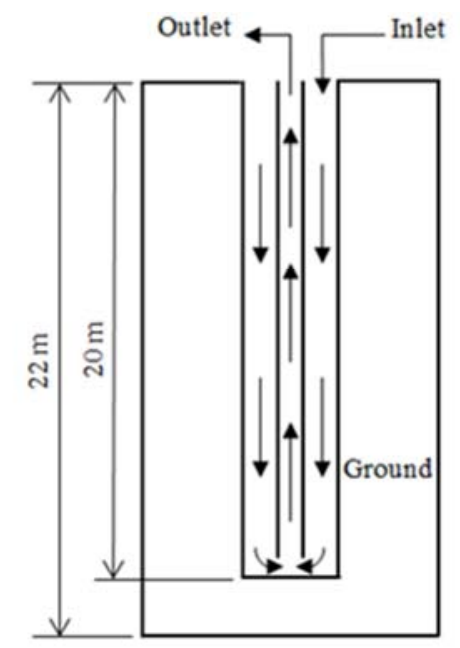

(a) Front view

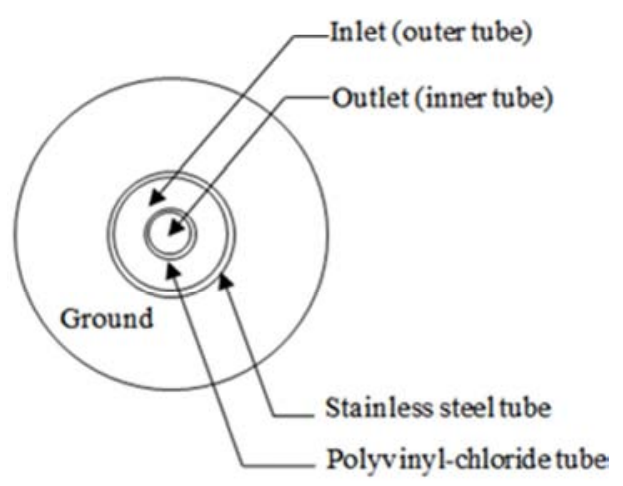

(b) Top view

Figure 1. Schematic diagram of the double tube GHE model: (a) Front view; (b) Top view. 


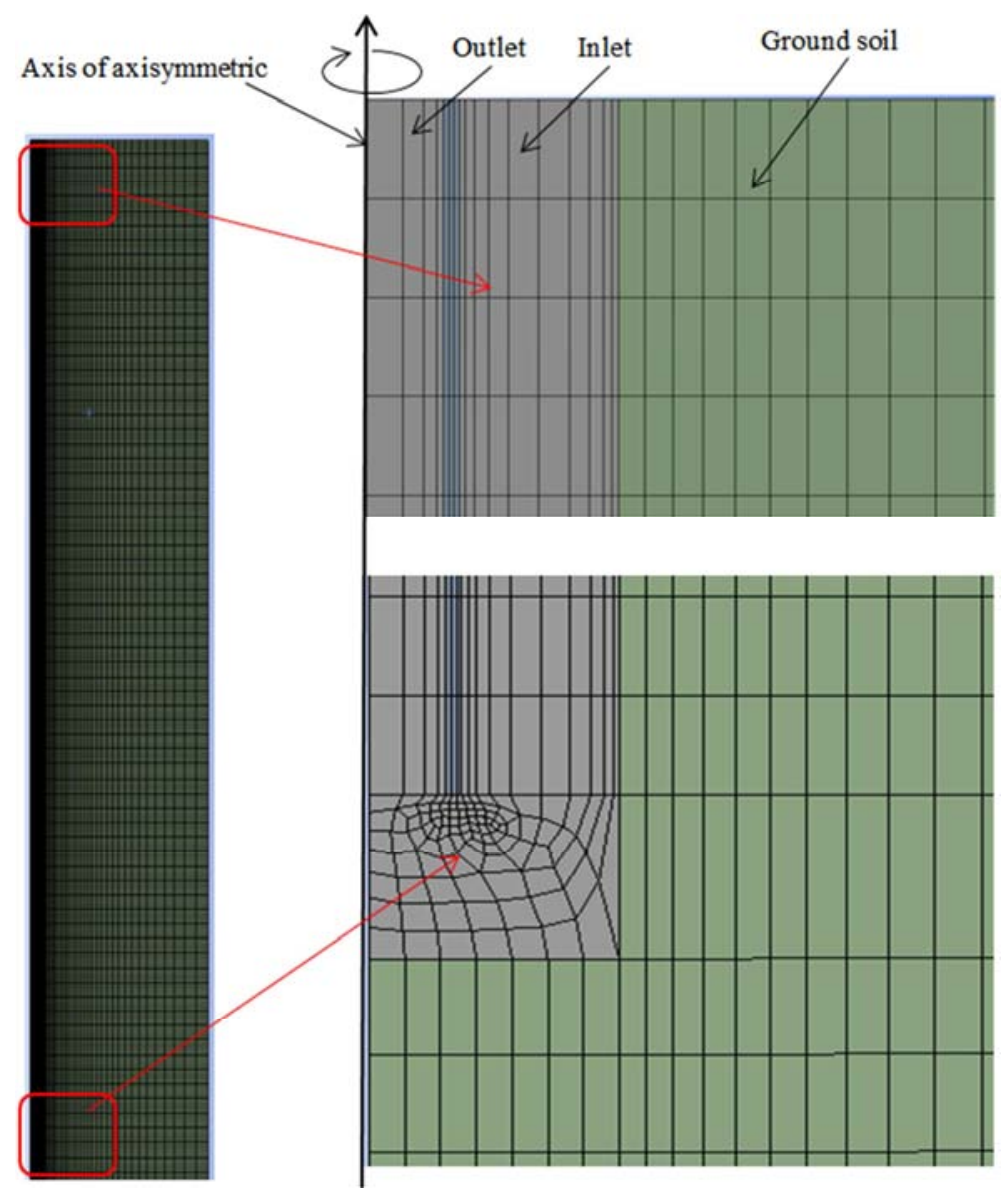

Figure 2. The example pattern of mesh of double tube GHE and ground soil.

In order to reduce the number of the total mesh and obtain an accurate result, the mesh around and inside the GHE tubes was densified, while the mesh size far away from the GHE tube was gradually enlarged. The geometrical configurations of all models are shown in Table 1 and thermo-physical properties of materials used in simulation models are listed in Table 2. Ground profile up to $15 \mathrm{~m}$ in depth is Clay and below $15 \mathrm{~m}$ is Sandy-clay [20]. Water was used as the heat transfer fluid.

Table 1. Geometric specification of GHE models.

\begin{tabular}{lllll}
\hline Model & $\begin{array}{l}\text { Inlet (outer) tube diameter } \\
(\mathbf{m m})\end{array}$ & $\begin{array}{l}\text { Inlet (inner) tube diameter } \\
(\mathbf{m m})\end{array}$ & Inlet tube thickness (mm) & Outlet tube thickness (mm) \\
\hline M1-1 & 130 & 40 & 5 & 4 \\
M1-2 & 100 & 40 & 5 & 4 \\
M1-3 & 70 & 40 & 5 & 4 \\
M2-1 & 130 & 30 & 5 & 4 \\
M2-2 & 100 & 30 & 5 & 4 \\
M2-3 & 70 & 30 & 5 & 4 \\
M2-4 & 60 & 30 & 5 & 4 \\
M2-5 & 50 & 30 & 5 & 4 \\
M3-1 & 130 & 20 & 5 & 4 \\
M3-2 & 100 & 20 & 5 & 4 \\
M3-3 & 70 & 20 & 5 & 4 \\
M3-4 & 60 & 20 & 5 & 4 \\
M3-5 & 50 & 20 & 5 & 4 \\
M3-6 & 40 & & 5 & 4 \\
\hline
\end{tabular}

Table 2. Materials thermo-physical properties used in numerical model [17, 18].

\begin{tabular}{llll}
\hline Material name & Density $\left(\mathbf{k g} / \mathbf{m}^{\mathbf{3}}\right)$ & Specific heat $(\mathbf{J} / \mathbf{k g}-\mathbf{K})$ & Thermal conductivity $(\mathbf{W} / \mathbf{m}-\mathbf{K})$ \\
\hline Stainless steel (inlet tube) & 7817 & 460 & 13.8 \\
Polyvinyl chloride (outlet tube) & 1380 & 960 & 0.15 \\
Clay & 1700 & 1800 & 1.2 \\
Sandy-clay & 1960 & 1200 & 2.1 \\
\hline
\end{tabular}




\subsection{Numerical Method for Optimization}

To optimization of double tube vertical GHE, numerical simulations were carried out by using the commercial CFD software ANSYS FLUENT 17.2 [21]. The governing equations are as follows [22]:

For 2D axisymmetric geometries, the continuity equation is given by

$$
\frac{\partial \rho}{\partial t}+\frac{\partial}{\partial x}\left(\rho v_{x}\right)+\frac{\partial}{\partial r}\left(\rho v_{r}\right)+\frac{\rho v_{r}}{r}=0
$$

where $\rho$ in density, $t$ is time, $x$ is axial coordinate, $r$ is radial coordinate, $v_{x}$ is axial velocity and $v_{r}$ is radial velocity.

The axial and radial momentum conservation equations of 2D axisymmetric geometries are given by Eq. (2) and (3)

$$
\begin{gathered}
\frac{\partial}{\partial t}\left(\rho v_{x}\right)+\frac{1}{r} \frac{\partial}{\partial x}\left(r \rho v_{x} v_{x}\right)+\frac{1}{r} \frac{\partial}{\partial r}\left(r \rho v_{r} v_{x}\right)=-\frac{\partial p}{\partial x}+ \\
\frac{1}{r} \frac{\partial}{\partial x}\left[r \mu\left(2 \frac{\partial v_{x}}{\partial x}-\frac{2}{3}(\nabla \cdot \vec{v})\right)\right]+\frac{1}{r} \frac{\partial}{\partial r}\left[r \mu\left(\frac{\partial v_{x}}{\partial r}+\frac{\partial v_{r}}{\partial x}\right)\right] \\
\frac{\partial}{\partial t}\left(\rho v_{r}\right)+\frac{1}{r} \frac{\partial}{\partial x}\left(r \rho v_{x} v_{r}\right)+\frac{1}{r} \frac{\partial}{\partial r}\left(r \rho v_{r} v_{r}\right)=-\frac{\partial p}{\partial r}+\frac{1}{r} \frac{\partial}{\partial x}\left[r \mu \left(\frac{\partial v_{r}}{\partial x}+\right.\right. \\
\left.\left.\frac{\partial v_{x}}{\partial r}\right)\right]+\frac{1}{r} \frac{\partial}{\partial r}\left[r \mu\left(2 \frac{\partial v_{r}}{\partial r}-\frac{2}{3}(\nabla \cdot \vec{v})\right)\right]-2 \mu \frac{v_{r}}{r^{2}}+\frac{2}{3} \frac{\mu}{r}(\nabla \cdot \vec{v})
\end{gathered}
$$

where $\mu$ is viscosity, $\mathrm{p}$ is pressure and $\nabla \cdot \vec{v}=\frac{\partial v_{x}}{\partial x}+\frac{\partial v_{r}}{\partial r}+\frac{v_{r}}{r}$

The energy equation is given by

$$
\frac{\partial(\rho h)}{\partial t}-\frac{\partial p}{\partial t}+\nabla \cdot(\rho \vec{v} h)=\nabla\left[\left(\mu+\frac{\mu_{t}}{\sigma_{t}}\right) \nabla h\right]
$$

where $h$ is enthalpy, $\mu_{t}$ is turbulence viscosity, $\sigma_{t}$ is constant.

In ground soil region, the energy transport equation given by

$$
\rho_{s} C_{p} \frac{\partial T}{\partial t}=\nabla \cdot(k \nabla T)
$$

where $\rho_{s}$ is density of soil, $C_{p}$ is specific heat of soil, $k$ is thermal conductivity of soil and $T$ is temperature.

The numerical simulations were carried out for laminar flow and turbulent flow considering three mass flow rates as 1 , 7 and 35 lit $/ \mathrm{min}$. The SIMPLE algorithm was used for the velocity-pressure coupling. To describe the fluid flow field, finite-volume formulation was used to solve the Navier-Stokes equations. Since heat transfer fluid in the simulation models is incompressible fluid water, hence the Realizable $\mathrm{k}-\varepsilon$ model with standard wall functions was considered for the case of turbulent flow [23]. The models were simulated in the cooling mode for continuous $24 \mathrm{~h}$ operation by applying the physical and thermal properties of materials listed in Table 2.

\subsection{Boundary and Initial Conditions}

A constant and uniform temperature $302 \mathrm{~K}$ was applied to the top surface of the ground. At the bottom, a heat flux 65 $\mathrm{mW} / \mathrm{m}^{2}$ [24] was used. The outer surface of ground at a distance $3.0 \mathrm{~m}$ from the center line was considered no heat flux. Ground temperatures variation up-to $10.0 \mathrm{~m}$ depth at different depth positions measured on July 1, 2016 in Saga
University, Japan is shown in Fig. 3(a). The ground temperature influenced strongly up-to level $5 \mathrm{~m}$ in depth by ambient temperature and below that ground temperature assumed to be constant of $290 \mathrm{~K}$. For cooling mode of operation, the initial ground temperature was assumed to be similar with the ground temperature measured on July 1, 2016 Then the simulation models were initialized with the temperature profile shown in Fig. 3(a). After initialization, the temperature contour is shown in Fig. 3(b). The inlet water temperature was set to $300 \mathrm{~K}$; the inlet and outlet were considered as the velocity-inlet and outflow. Three mass flow rates 1,7 and $35 \mathrm{lit} / \mathrm{min}$ were considered and the inlet velocity magnitude for each model was set corresponding to mass flow rates of 1, 7 and $35 \mathrm{lit} / \mathrm{min}$. Corresponding to these mass flow rates, the simulation conditions and the fluid flow regimes are summarized in Table 3.

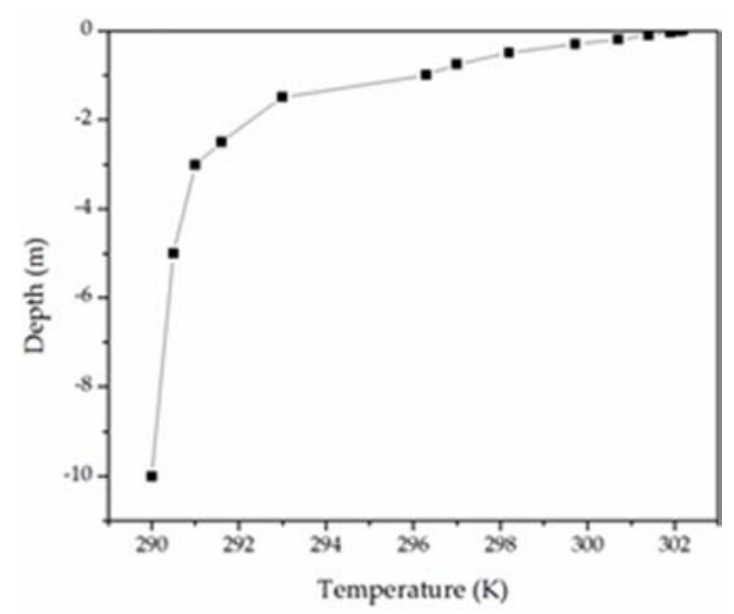

(a) Ground temperature profile

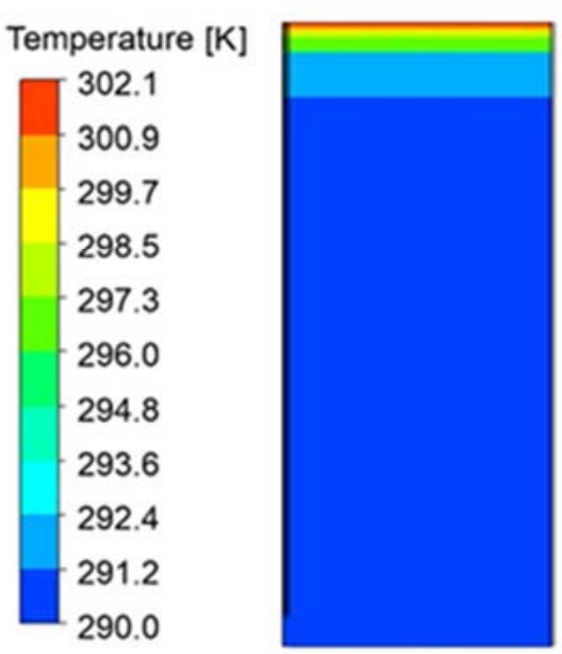

(b) Temperature contour

Figure 3. Initial condition for simulation models (a) ground temperature profile; (b) temperature contour. 
Table 3. Simulation conditions and fluid flow regime for all of the simulation models.

\begin{tabular}{lllllll}
\hline Case & $\begin{array}{l}\text { Mass flow rate } \\
\text { (lit/min) }\end{array}$ & $\begin{array}{l}\text { Inlet water } \\
\text { temperature (K) }\end{array}$ & $\begin{array}{l}\text { Reynolds number in } \\
\text { inlet tube }\end{array}$ & $\begin{array}{l}\text { Reynolds number in } \\
\text { outlet tube }\end{array}$ & $\begin{array}{l}\text { Flow regime in inlet } \\
\text { tube }\end{array}$ & $\begin{array}{l}\text { Flow regime in } \\
\text { outlet tube }\end{array}$ \\
\hline 1 & 1 & 300 & $\leq 2300$ & $\leq 2300$ & Laminar & Laminar \\
2 & 7 & 300 & $\leq 2300$ & $\geq 4000$ & Laminar & Turbulent \\
3 & 35 & 300 & $\geq 4000$ & $\geq 4000$ & Turbulent & Turbulent \\
\hline
\end{tabular}

\subsection{Mesh Elements Independence Test}

To perform the grid independence test, four sets of grid such as 16635, 24510, 46645 and 122413 elements were considered. The model M1-1 was simulated with mass flow rate $2 \mathrm{lit} / \mathrm{min}$, inlet water temperature $300 \mathrm{~K}$. After $24 \mathrm{~h}$ operation, the outlet temperatures were $295.70 \mathrm{~K}, 295.67 \mathrm{~K}$, $295.64 \mathrm{~K}$ and $295.61 \mathrm{~K}$ respectively for $16635,24510,46645$ and 122413 elements. For all of the elements number, outlet temperature after $24 \mathrm{~h}$ operation very closed to each other. With increasing the elements number, outlet temperature little change. Therefore 46645 grid system was used in this study.

\subsection{Model Validation}

Comparison between simulation and experimental results are needed for better understanding of acceptance of the numerical results. To confirm reliability of numerical simulation models implemented in present study, the heat transfer rate obtained from present simulation results were compared with experimental and numerical results of Jalaluddin et al. [17, 18]. For comparison with previous results, the assumptions used i.e., (i) hybrid mesh generation method; (ii) CFD code; (iii) similar parameters; (iv) similar boundary conditions and initial conditions; (v) experimental data in site. In the previous test $[17,18]$, the inlet and outlet tube diameter were $130 \mathrm{~mm}$ and $40 \mathrm{~mm}$; GHE length was $20 \mathrm{~m}$; the inlet water temperature was 300 $\mathrm{K}$; mass flow rates of water were 2,4 and $8 \mathrm{lit} / \mathrm{min}$; the operation time was $24 \mathrm{~h}$ and materials properties were same as listed in Table 2. The heat transfer rates of present model M1-1 were compared with previous [17, 18] heat transfer rates under above mentioned similar conditions. The average heat transfer rates for 2, 4 and $8 \mathrm{lit} / \mathrm{min}$ were 36.9 , 49.6 and $54.8 \mathrm{~W} / \mathrm{m}$ respectively $[17,18]$. On the other hand in present simulation model M1-1, the corresponding heat transfer rates are $37.7,51.7$ and $55.3 \mathrm{~W} / \mathrm{m}$ respectively for 2 , 4 and $8 \mathrm{lit} / \mathrm{min}$. The deviations of heat transfer rate are 2.1 , 4.2 and $0.9 \%$ respectively for mass flow rate 2,4 and 8 lit/min. For simplicity, Fig. 4 shows the comparison of heat transfer rate per meter borehole length of present simulation result and results from Jalaluddin et al. $[17,18]$ for mass flow rate $4 \mathrm{lit} / \mathrm{min}$. The present numerical result in Fig. 4 shows the similar trend with Jalaluddin's experimental and numerical results and deviation is within $4.2 \%$. This confirmed that the good agreement of simulation model results with previous results.

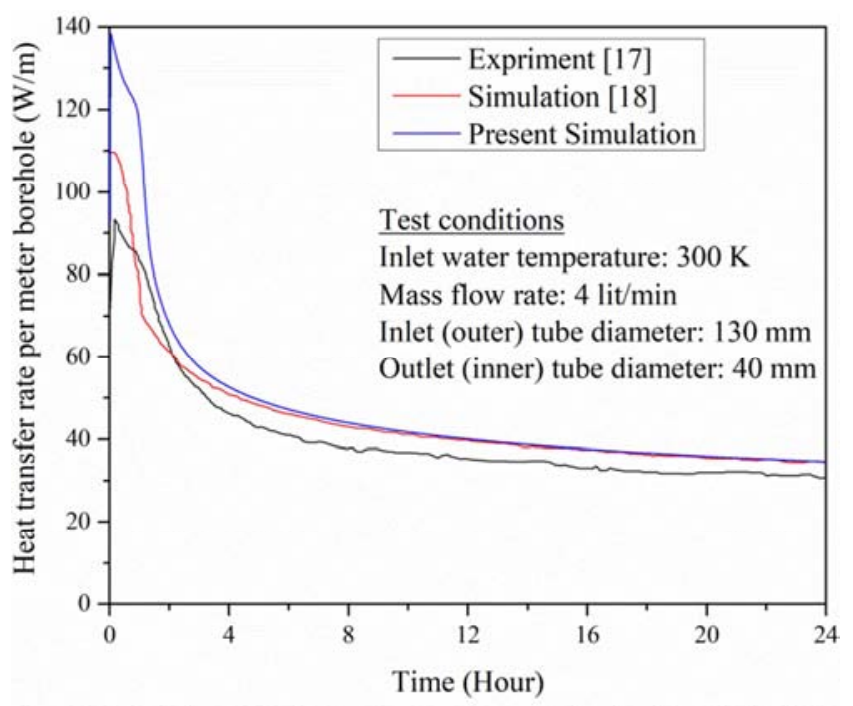

Figure 4. Validation of present numerical model with the data from Jalaluddin et al. $[17,18]$ for mass flow rate 4 lit/min.

\section{Results and Discussion}

\subsection{Selection of Inlet and Outlet}

Before starting the optimization simulation of double tube vertical GHEs, it is necessary to decide inlet in either inner tube or outer tube is more effective for heat transfer. Preliminary simulation was done for model M1-1 (outer annular tube diameter $130 \mathrm{~mm}$ and inner circular tube diameter $40 \mathrm{~mm}$ ) by alternating the inlet and outlet in outer tube and inner tube. Inlet water temperature was $300 \mathrm{~K}$, mass flow rates were 1 and $4 \mathrm{lit} / \mathrm{min}$ and boundary and initial conditions were similar described in section 2.3. It was observe that the average heat transfer rates in $24 \mathrm{~h}$ operation are 23.8 and $49.4 \mathrm{~W} / \mathrm{m}$ respectively for the mass flow rates of 1 and $4 \mathrm{lit} / \mathrm{m}$ when we considered inlet in outer annular tube and outlet in inner circular tube. On the other hand if we considered inlet in inner circular tube and tube in outer annular pipe the average heat transfer rates are 20.6 and $43.4 \mathrm{~W} / \mathrm{m}$ respectively for the mass flow rates 1 and $4 \mathrm{lit} / \mathrm{m}$. So inlet in outer annular tube and outlet at inner circular tube has been chosen for simulation of models.

\subsection{Heat Transfer Rate}

Heat transfer rates were calculated to investigate the thermal performance of the GHEs. Heat transfer rate can be calculated by follow:

$$
\mathrm{Q}=\mathrm{mC}_{\mathrm{p}} \Delta \mathrm{T}
$$


where $\mathrm{m}$ is the mass flow rate $(\mathrm{kg} / \mathrm{s}), \mathrm{C}_{\mathrm{p}}$ is the specific heat $(\mathrm{J} / \mathrm{kg} \mathrm{K})$, and $\Delta \mathrm{T}$ is the temperature difference between the inlet and outlet of circulated water $(\mathrm{K})$. Then heat transfer rate per meter borehole depth is defined as follow:

$$
\mathrm{q}=\mathrm{Q} / \mathrm{L}
$$

where $\mathrm{L}$ is the length of the borehole.

Heat transfer rate assessment in three criteria such as: (i)

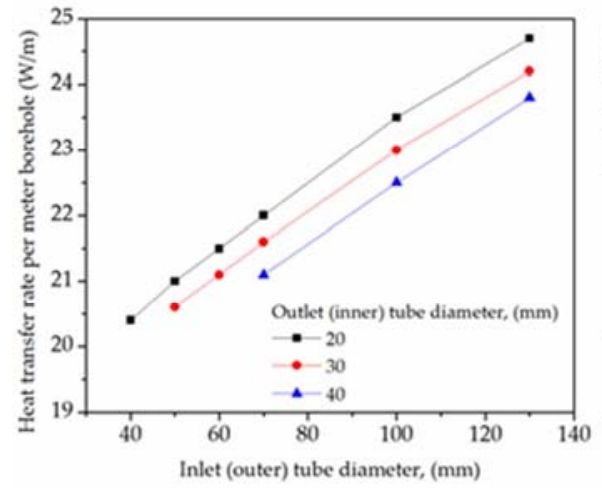

(a)

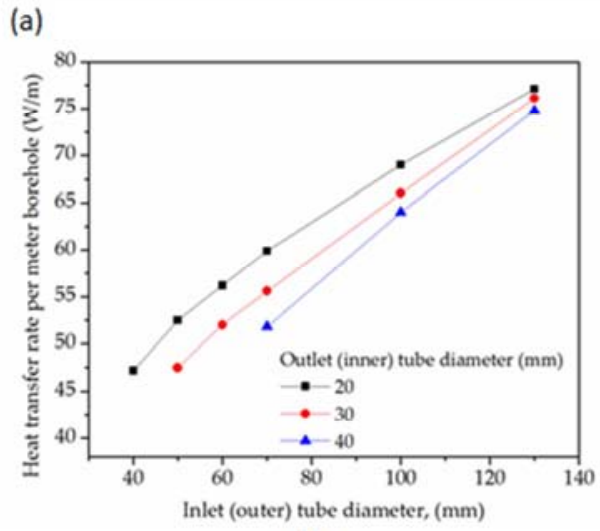

(c) laminar flow through both inlet and outlet tubes refereed as case 1; (ii) laminar flow through inlet tube, turbulent flow through outlet tube refereed as case 2; (iii) turbulent flow through both inlet and outlet tubes refereed as case 3. Fig. 5 shows the heat transfer rate per unit borehole length for all of the models in $24 \mathrm{~h}$ continuous operation and the average heat transfer rates of each flow rate for all of the models are summarized in Table 4.

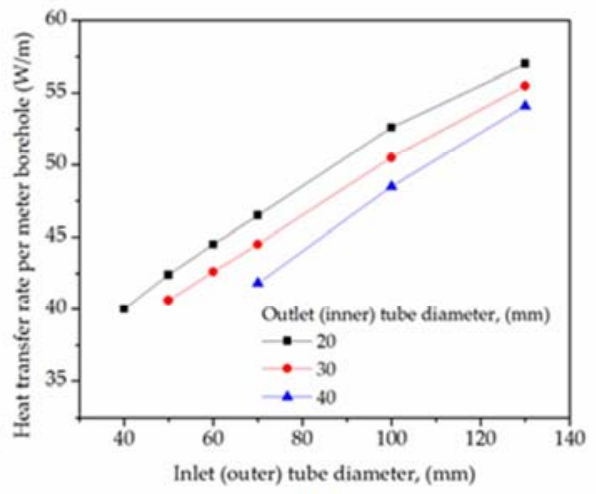

(b)

Figure 5. Average heat transfer rate per meter borehole of the GHE models (a) Laminar flow through inlet and outlet tube @ 1 lit/min; (b) Laminar flow through inlet tube and turbulentflowthrough outlet tube@7lit/min; (c)Turbulentflow through inlet and outlet tube@35lit/min.

Table 4. Average heat exchange rates of each of the model for cases $1,2 \& 3$.

\begin{tabular}{|c|c|c|c|}
\hline Model & \multicolumn{3}{|c|}{ Average heat transfer rate $(\mathrm{W} / \mathrm{m})$} \\
\hline & $1 \mathrm{lit} / \mathrm{min}$ & $7 \mathrm{lit} / \mathrm{min}$ & 35 lit/min \\
\hline M1-1 & 23.8 & 54.1 & 74.8 \\
\hline M1-2 & 22.5 & 48.5 & 64.0 \\
\hline M1-3 & 21.1 & 41.8 & 51.8 \\
\hline M2-1 & 24.2 & 55.5 & 76.1 \\
\hline M2-2 & 23.0 & 50.5 & 66.0 \\
\hline M2-3 & 21.6 & 44.5 & 55.6 \\
\hline M2-5 & 20.6 & 40.6 & 47.5 \\
\hline M3-1 & 24.7 & 57.0 & 77.1 \\
\hline M3-2 & 23.5 & 52.6 & 69.0 \\
\hline M3-3 & 22.0 & 46.5 & 59.9 \\
\hline M3-4 & 21.5 & 44.5 & 56.2 \\
\hline M3-5 & 21.0 & 42.4 & 52.5 \\
\hline M3-6 & 20.4 & 40.0 & 47.2 \\
\hline
\end{tabular}

From Fig. 5(a)-(c), it can be seen that heat transfer rate per meter borehole length increased with the increases of inlet tube diameter for a fixed outlet tube diameter. For example from Fig. 5(a), for the case 1 with inlet tube diameter $130 \mathrm{~mm}$ and outlet tube diameter $40 \mathrm{~mm}$ (model M1-1), the average heat transfer rate was $23.8 \mathrm{~W} / \mathrm{m}$, but when inlet tube diameter $70 \mathrm{~mm}$ and outlet tube diameter $40 \mathrm{~mm}$ (model M1-3), the heat transfer rate was $21.1 \mathrm{~W} / \mathrm{m}$. But this increases of heat 
transfer occurred with the increases overall size of the GHE which will increases the material cost and installation cost. On the other hand for a fixed inlet tube diameter, heat transfer rate increased with decreases of outlet tube diameter. For example in case 1 with fixed inlet tube diameter $130 \mathrm{~mm}$, the average heat transfer rate was $24.7 \mathrm{~W} / \mathrm{m}$ when outlet tube diameter 20 $\mathrm{mm}$ (model M3-1) and $23.8 \mathrm{~W} / \mathrm{m}$ when outlet tube diameter $40 \mathrm{~mm}$ (model M1-1). This happened because of the contact surface area between water and outlet tube decreases with the decreases of outlet tube diameter. This reduces the heat transfer between inlet tube and outlet tube. Similarly for the cases 2 and 3, there is some enhancement of heat transfer occurred by reducing the outlet tube diameters for a fixed inlet tube diameter. So there is an opportunity to reduce material cost of double tube GHE by reducing the outlet tube diameter for a fixed inlet diameter tube.

\subsection{Pressure Drop}

The pressure drop through all of the models is shown in Fig. 6. In order to verify the pressure drop through GHE tubes due to water flow, pressure drop also calculated by using following equations:

$$
\Delta P=f_{S}\left(\frac{L}{D_{H}}\right) \times\left(\frac{\rho V^{2}}{2}\right)
$$

where $\Delta P$ is the pressure $\operatorname{drop}(\mathrm{Pa}), f_{S}$ is the friction factor, $L$ is the tube length $(\mathrm{m}), D_{H}$ is the hydraulic diameter of tube $(\mathrm{m}), \rho$ is the density of fluid $\left(\mathrm{kg} / \mathrm{m}^{3}\right), V$ is the fluid velocity $(\mathrm{m} / \mathrm{s})$.

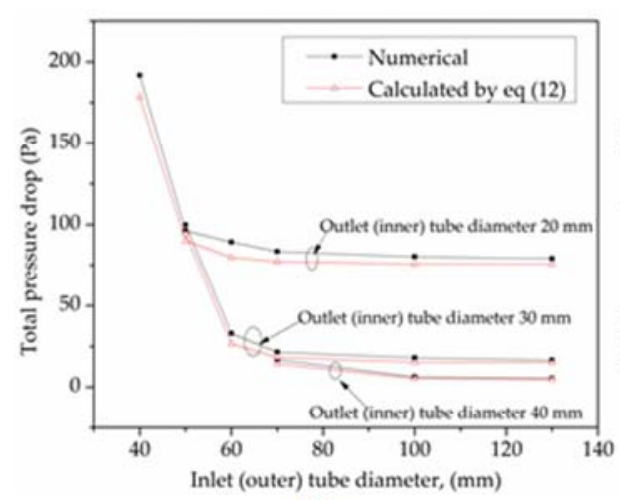

(a)
For straight tube, friction factor can be calculated by Hagen-Poiseuille equation for laminar flow

$$
f_{s}=\frac{64}{R e}
$$

and by Blasius equation for turbulent flow

$$
f_{S}=\frac{0.316}{R e^{0.25}}
$$

Also pressure drop caused by sudden contraction when water enters in outlet tube from inlet tube can be calculated by:

$$
\Delta P_{c}=\frac{\rho\left(V_{o}-V_{i}\right)^{2}}{2}
$$

where $V_{o}$ is the velocity in outlet tube and $V_{i}$ is the velocity in inlet tube.

Then the total pressure drop through the GHE is calculated by

$$
\Delta P_{\text {total }}=\Delta P_{\text {inlet tube }}+\Delta P_{\text {outlet pipe }}+\Delta P_{c}
$$

Fig. 6 also included the calculated values of pressure drops by using Eq. (12). The pressure drop through GHE tube increased with increase of flow rate and with the decrease of GHEs tube diameter. This indicates that increases of pump work of GSHP system. Table 5 summarized the simulated pressure drop through GHE models. From Fig. 6(a)-(c) it can be seen that the numerical pressure drops slightly higher than that of calculated pressure drops through GHE models.

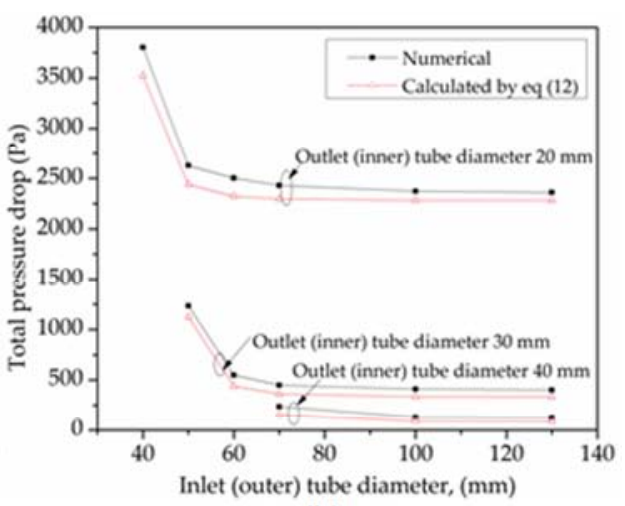

(b)

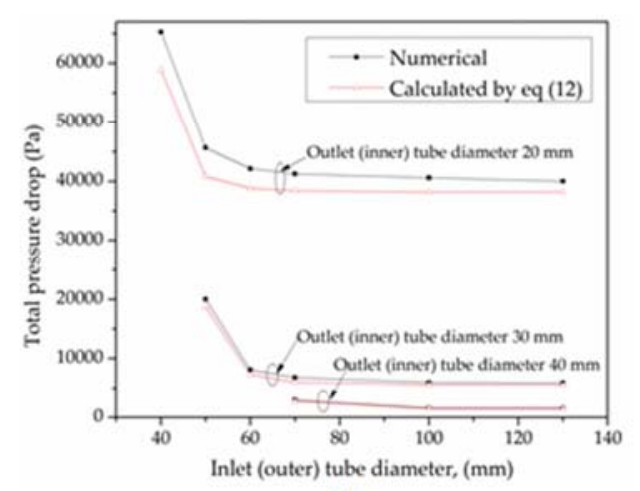

(c)

Figure 6. Pressure drop through the GHE models (a) Laminar flow through inlet and outlet tube @ 1 lit/min; (b) Laminar flow through inlet tube and turbulent flow through outlet tube@7lit/min; (c)Turbulent flow through inlet and outlet tube@35lit/min. 
Table 5. Pressure drop from numerical simulation of each of the model for cases $1,2 \& 3$.

\begin{tabular}{|c|c|c|c|}
\hline \multirow{2}{*}{ Model } & \multicolumn{3}{|c|}{ Pressure drop (Pa) } \\
\hline & $1 \mathrm{lit} / \mathrm{min}$ & $7 \mathrm{lit} / \mathrm{min}$ & $35 \mathrm{lit} / \mathrm{min}$ \\
\hline M1-1 & 5.4 & 125 & 1498 \\
\hline M1-2 & 6.2 & 130 & 1537 \\
\hline M1-3 & 16.8 & 235 & 2907 \\
\hline M2-1 & 16.5 & 401 & 5897 \\
\hline M2-2 & 17.9 & 411 & 5981 \\
\hline M2-3 & 21.5 & 448 & 6815 \\
\hline M2-4 & 32.9 & 549 & 8110 \\
\hline M2-5 & 99.8 & 1233 & 20022 \\
\hline M3-1 & 79.1 & 2361 & 40001 \\
\hline M3-2 & 80.3 & 2374 & 40587 \\
\hline M3-3 & 83.4 & 2430 & 41252 \\
\hline M3-4 & 89.2 & 2503 & 42137 \\
\hline M3-5 & 96.2 & 2628 & 45683 \\
\hline M3-6 & 191.8 & 3802 & 65278 \\
\hline
\end{tabular}

\subsection{Optimization Evaluation}

Based on the simulation results shown in Fig. 5 and summarized in Table 4, it was discussed in section 3.2 that the reduction of outlet tube diameter helps to improve the thermal performance of double tube vertical GHE. Also reduction of inlet tube diameter is possible considering small decreases of heat transfer rate at low mass flow rate especially in laminar flow (case 1 for example). In the laminar flow both in inlet tube and outlet tube with mass flow rate 1 lit/min (case 1), heat transfer rate decreased only $14 \%$ for the model M3-6 compare to the model M1-1. When water flow is laminar in inlet tube and turbulent in outlet tube with mass flow rate $7 \mathrm{lit} / \mathrm{min}$ (case 2), the heat transfer rate decreased $26 \%$ for the model M3-6 compare to the model M1-1. The corresponding decreased of heat transfer rate is $36 \%$ when turbulent flow both in inlet and outlet tube with the mass flow rate $35 \mathrm{lit} / \mathrm{min}$ (case 3 ). Thus with increasing the mass flow rate from laminar to turbulent, the decreasing rate of heat transfer rate increases when compared between the models M1-1 and M3-6. Based on the model M3-6, with increasing the mass flow rate from laminar to turbulent, the decreasing rate of heat transfer rate similarly increased for all other models. Even if the heat transfer rate decreased $14 \%$ in the case 1 for model M3-6 compare to model M1-1, the inlet tube diameter can be reduced from 130 $\mathrm{mm}$ to $40 \mathrm{~mm}$ and outlet tube diameter from $40 \mathrm{~mm}$ to $20 \mathrm{~mm}$. On the other hand the heat transfer rate decreased $16 \%$ in the case 1 for model M3-6 compare to model M2-1, the inlet tube diameter can be reduced from $130 \mathrm{~mm}$ to $40 \mathrm{~mm}$ and outlet tube diameter from $30 \mathrm{~mm}$ to $20 \mathrm{~mm}$. Thus it is better to reduce the outlet (inner) tube diameter for a fixed inlet (outer) tube diameter on the basis of heat transfer rate. Also in case 1, if we compare between model M3-1 and M3-6, the heat transfer rate decreased $17 \%$ but we can reduce the inlet tube diameter from $130 \mathrm{~mm}$ to $40 \mathrm{~mm}$ with fixed outlet tube diameter $20 \mathrm{~mm}$. The heat transfer rate decreased $13 \%$ for model M3-6 compare to model M3-2 in case 1, but reduction of the inlet tube diameter from $100 \mathrm{~mm}$ to $40 \mathrm{~mm}$ is possible with fixed outlet tube diameter $20 \mathrm{~mm}$. Similarly based on the model M3-6, for all other models from M3-1 to M3-5, with decreasing the inlet (outer) tube diameter the decreasing rate of heat transfer rate gradually decreased.

It is obvious that with increases of mass flow rate, heat transfer rate will also be increased. However, from Figs. 5 and 6 and Tables 4 and 5, any improvement of heat transfer or reductions of the size of GHE are always included a penalty of pressure drop. From Fig. 6 and Table 5, the pressure drops of all models are in low range (5.4 to $191.8 \mathrm{~Pa}$ ) for the case 1 when inlet and outlet tube flow was in laminar. Pressure drop significantly increased when flow rate increased from 1 lit/min (both inlet and outlet tube flow laminar) to $7 \mathrm{lit} / \mathrm{min}$ (inlet tube flow laminar and outlet tube flow turbulent). And pressure drops are very high when both inlet and outlet tube flow in turbulent (case $3 @ 35$ lit $/ \mathrm{min}$ ). Pressure drops also increased with decrease of inlet and outlet tube diameter of GHE models for a fixed mass flow rate.

In order to achieve an energy savings by reducing the inlet and outlet diameter of double tube vertical GHE, the balance between heat transfer and pressure drop needed to examine. For instance, for model M1-1, the heat transfer rate increased 2.3 times and 3.1 times respectively when mass flow rate increased from $1 \mathrm{lit} / \mathrm{min}$ to $7 \mathrm{lit} / \mathrm{min}$ and $1 \mathrm{lit} / \mathrm{min}$ to $35 \mathrm{lit} / \mathrm{min}$. The pressure drop increased 23.1 times and 277.4 times respectively corresponding increases of mass flow rate increased from $1 \mathrm{lit} / \mathrm{min}$ to $7 \mathrm{lit} / \mathrm{min}$ and $1 \mathrm{lit} / \mathrm{min}$ to $35 \mathrm{lit} / \mathrm{min}$. Similar characteristics of increased of the heat transfer rate and pressure drop can be observed from Table 4 and 5 for all of the models. So it is better to operate the double tube vertical GHE in laminar flow condition which will save high pump work as well as save selection of high capacity pump and operating cost. In this case just we have to concern about small decreasing rate of heat transfer rate. For instance, in the case of laminar flow both in inlet tube and outlet tube with mass flow rate $1 \mathrm{lit} / \mathrm{min}$ (case 1), the pressure drop increased 2.4 times and heat transfer rate decreased 1.2 times for model M3-6 compared to model M3-1. Importance of this penalty of pressure drop and heat transfer rate reduced the inlet tube diameter from $130 \mathrm{~mm}$ to $40 \mathrm{~mm}$ fixed outlet tube diameter. Therefore, the heat transfer rate and pressure drop are related to both the mass flow rate (Reynolds number) and size of the GHE, it is best option to install smaller diameter (M3-6 for example) double tube vertical GHE and operate in laminar flow condition.

The coefficient of performance (COP) improvement criterion proposed by Jalaluddin and Miyara [16] has been assumed to evaluate the energy balance between heat transfer rate and pressure drop. The COP improvement criterion was calculated from the following equation:

$$
\frac{Q^{\prime} H}{Q_{H}}-\frac{V \Delta p}{Q_{H}} \frac{\Delta p \prime}{\Delta p}>0
$$

where $Q_{H}$ is heating rate $(\mathrm{W} / \mathrm{m}), Q_{H}^{\prime}$ is increases of heating rate $(\mathrm{W} / \mathrm{m}), V$ is volumetric flow rate $\left(\mathrm{m}^{3} / \mathrm{s}\right), \Delta P$ is pressure drop $(\mathrm{Pa})$ and $\Delta P^{\prime}$ is increases of pressure drop $(\mathrm{Pa})$. To evaluate the COP performance criteria simulations were carried out for our present 4 different models such as M1-3, 
M2-3, M3-3 and M3-6 using similar boundary conditions and properties of U-tube GHE [16]. We considered lower size double tube GHE. Because, if the lower size GHEs improve the COP criterion, than other higher size GHEs obviously will improve the COP criterion. By using Eq. (13), the COP improvement criterions are listed in Table 6. The COP improvement criterions were analyzed on the basis of U-tube GHE data with flow rate of 2 lit/min [16].

In the case of U-tube GHE [16], the minimum borehole diameter was $86 \mathrm{~mm}$. In the present double tube GHE, if we select inlet (outer) tube diameter $70 \mathrm{~mm}$, then borehole diameter required $80 \mathrm{~mm}$ because thickness of tube is $5 \mathrm{~mm}$. And for other lower size inlet tube GHEs, borehole diameter will also be lowered. But COP improvement criterions for double tube in Table 6 have shown always positive. The positive value of Eq. (13) in Table 6 indicates net COP improved. Within the present simulation models, reduced size of double tube vertical GHE effective for GSHP system even if pressure drop increased and heat transfer rate little decreased with the size reduction.

Table 6. The COP improvement criterion defined in Eq. (8) with mass flow rate 2 lit/min.

\begin{tabular}{|c|c|c|c|c|c|c|c|c|}
\hline \multirow{2}{*}{ Model } & $\mathbf{Q}_{\text {Double tube }}$ & $Q_{H}[14]$ & $\mathbf{Q}_{H}^{\prime}$ & $\mathbf{V}$ & $\Delta \mathbf{P}_{\text {Double tube }}$ & $\Delta P[14]$ & $\Delta \mathbf{P}^{\prime}$ & \multirow{2}{*}{ Eq. (13) } \\
\hline & $\mathbf{W} / \mathbf{m}$ & & & $\mathrm{m}^{3} / \mathrm{s}$ & $\mathrm{Pa} / \mathrm{m}$ & & & \\
\hline M1-3 & 20.0 & 14.1 & 5.9 & $3.3333 \mathrm{E}-5$ & 2.3 & 3.1 & -0.8 & 0.42 \\
\hline M2-3 & 20.2 & 14.1 & 6.1 & $3.3333 \mathrm{E}-5$ & 3.1 & 3.1 & 0.0 & 0.43 \\
\hline M3-3 & 20.5 & 14.1 & 6.4 & $3.3333 \mathrm{E}-5$ & 9.4 & 3.1 & 6.3 & 0.45 \\
\hline M3-6 & 17.3 & 14.1 & 3.2 & $3.3333 \mathrm{E}-5$ & 19.2 & 3.1 & 16.1 & 0.23 \\
\hline
\end{tabular}

\subsection{Effect of GHE Materials on Heat Transfer}

High density polyethylene (HDPE) tube is usually used in installation of GHEs. However, copper tubing has been successfully used in some applications since copper tube has a very high thermal conductivity [4]. The effect of different tube materials on heat transfer rate with mass flow rate $1 \mathrm{lit} / \mathrm{min}$ was investigated and compared as shown in Fig. 7. Inlet (outer) tube with HDPE (density of $955 \mathrm{~kg} / \mathrm{m}^{3}$, specific heat of $2300 \mathrm{~J} / \mathrm{kg} \cdot \mathrm{K}$, thermal conductivity of $0.461 \mathrm{~W} / \mathrm{m} \cdot \mathrm{K}$ ), copper (density of 8978 $\mathrm{kg} / \mathrm{m}^{3}$, specific heat of $381 \mathrm{~J} / \mathrm{kg} \cdot \mathrm{K}$, thermal conductivity of $387.6 \mathrm{~W} / \mathrm{m} \cdot \mathrm{K}$ ) and stainless steel (SS) were considered. Outlet (inner) tube was considered as polyvinyl chloride (PVC) tube which was common for HDPE, copper and stainless steel inlet tube. Properties of SS and PVC have given in Table 2.

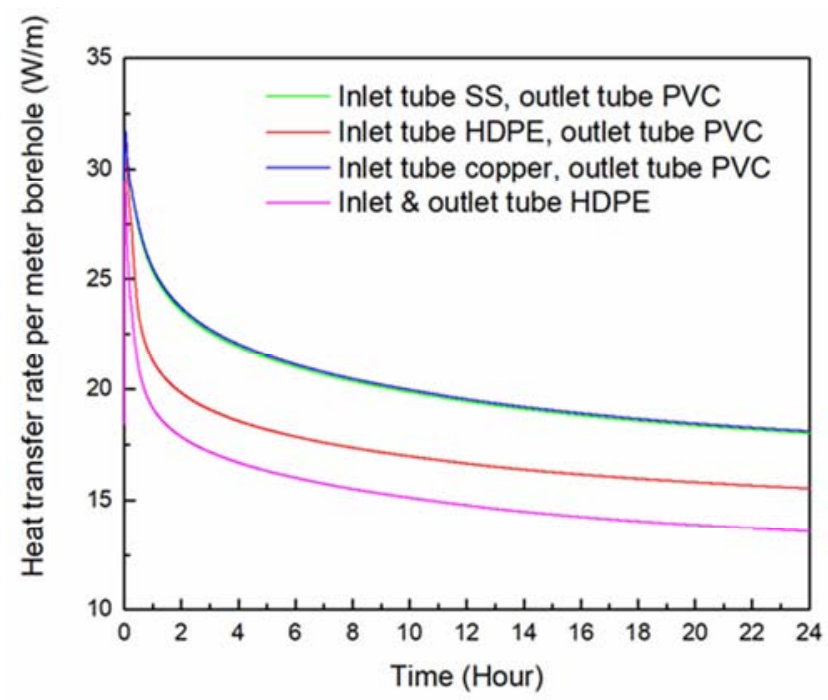

Figure 7. Effect of GHE materials on heat transfer rate.

The average heat transfer rates in $24 \mathrm{~h}$ continuous operation were $20.4 \mathrm{~W} / \mathrm{m}$ for inlet tube SS and outlet tube PVC; $20.6 \mathrm{~W} / \mathrm{m}$ for inlet tube copper and outlet tube PVC; 17.3 W/m for inlet tube HDPE and outlet tube PVC and 15.3
$\mathrm{W} / \mathrm{m}$ for both inlet and outlet tube HDPE. The average heat transfer rate for both SS and copper tube GHE are almost similar. The practical viewpoint is that even though the thermal conductivity of copper is very higher than that of SS, the heat transfer is dominated by surrounding ground soil around the GHE. The GHE with HDPE inlet tube and PVC outlet tube has $13 \%$ higher heat transfer rate in contrast GHE with HDPE in both inlet and outlet tube in $24 \mathrm{~h}$ operation. The reason is less heat interaction between inner and outer tube water when lower thermal conductivity material PVC was used as inner tube. Though the heat transfer rate is higher of copper tube and SS tube compared to HDPE tube, but copper tube and SS tube must have to be protected from corrosion in terms durability and corrosion resistance. Even though copper tube and SS tube protected from corrosion by using thin coating of corrosion resistance material, the high cost of copper and SS compare HDPE and PVC should be considered. And also the overall thermal conductivity of thin coated copper tube and SS tube necessarily need to calculate before selection.

\subsection{Effect of Long Time Operation on Ground Soil Temperature Around $\mathrm{GHE}$}

The simulation was conducted for model M3-6 (inlet tube diameter $40 \mathrm{~mm}$, outlet tube diameter $20 \mathrm{~mm}$ ) under 90 days of continuous operation with mass flow rate $1 \mathrm{lit} / \mathrm{min}$ (case-1) to observe the temperature variation of ground soil at different depth around the GHEs. All of the boundary and initial conditions are same as mentioned in section 2.3 except top surface of the ground. In the top surface heat flux boundary condition was applied which was measured in Saga University, Japan from July 1, 2016 to September 30, 2016 shown in Fig. 8. The affected zone around the GHE at different depth is shown in Fig. 9. The ground temperatures near the surface of the ground affected by top surface heat flux. In vertical direction, the affected region around GHE increased with operation time. For instance the ground temperature around GHE affected at $10 \mathrm{~m}$ depth was about $1.2 \mathrm{~m}$ after 30 days, 
$1.25 \mathrm{~m}$ after 60 days and 1.28 after 90 days respectively in radial direction. On the other hand at $15 \mathrm{~m}$ depth was about $1.05 \mathrm{~m}$ after 30 days, $1.10 \mathrm{~m}$ after 60 days and 1.13 after 90 days respectively in radial direction. So it is possible to install multiple double tube vertical GHE placing at $2.0 \mathrm{~m}$ lateral distance. But it depends on the operation time and mass flow rate. Also thermal interference should be considered especially in upper region near ground surface which can be analyzed by $3 \mathrm{D}$ simulation.

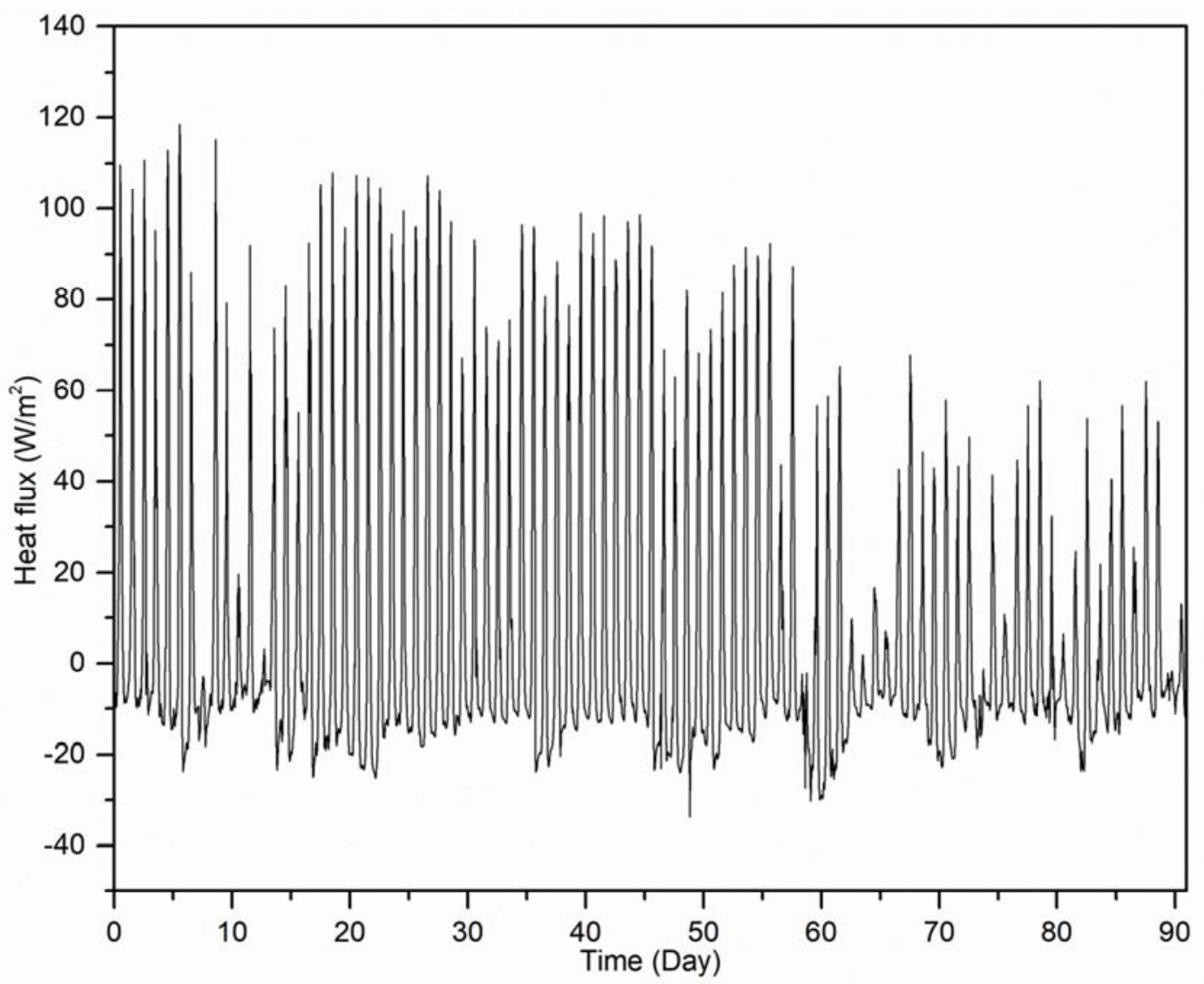

Figure 8. Ground surface heat flux measured Saga University, Japan from July 1, 2016 to September 30, 2016.

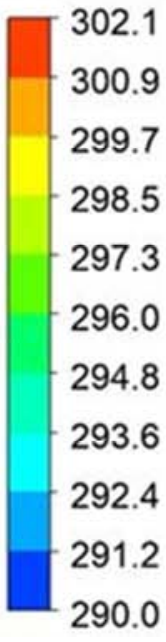

Temperature $[\mathrm{K}]$

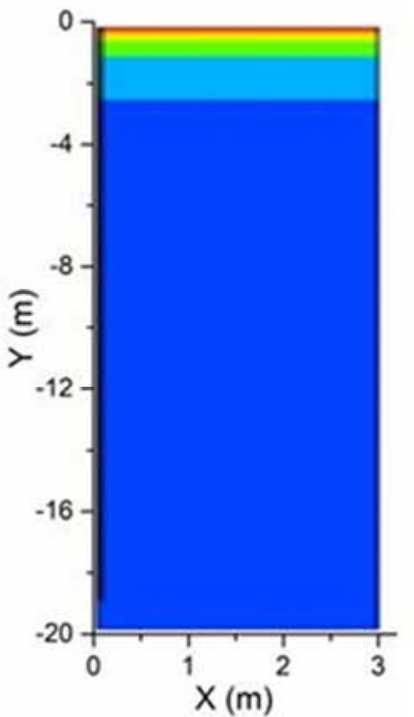

(a)

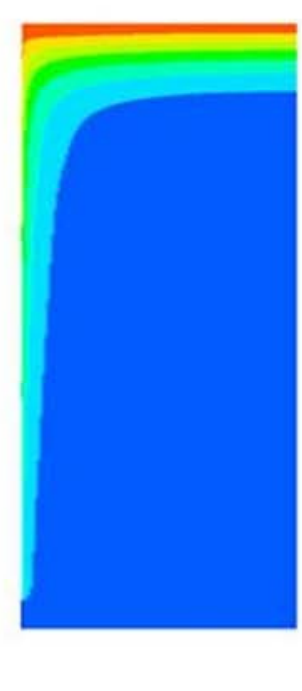

(b)

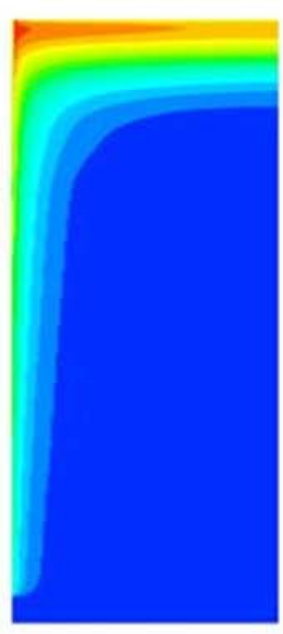

(c)

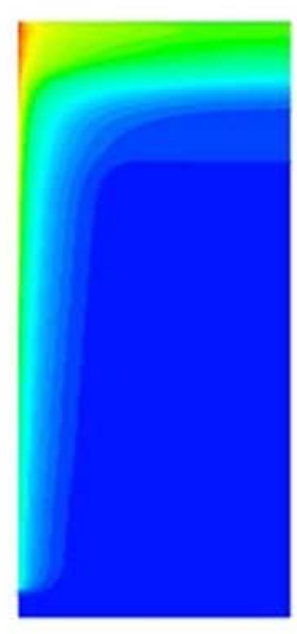

(d)

Figure 9. Contour of ground temperature distribution under 90 days continuous operation (a) initial condition; (b) after 30 day; (c) after 60 day; (d) after 90 day. 


\section{Conclusion}

In this study, the tow-dimensional axisymmetric transient heat transfer of double tube vertical GHE has been studied numerically. Before optimization, the model was validated with previous experimental and numerical results. The results of a numerical study of optimization of double tube vertical GHEs have been done by considering heat transfer rates and pressure drops. Effect of the different materials on heat transfer also discussed. Long time operation was discussed to observe the ground temperature variation around GHE at several radial and vertical distances.

The double tube vertical GHEs are more effective in laminar flow condition considering balance between heat transfer and pressure drop. Since in laminar flow region, pressure drop is not significantly high for our simulation models, if operate the vertical GHE in laminar flow condition, it is possible to reduce the inlet and outlet diameter of GHEs. The heat transfer rate decreased only $17.4 \%$ but the inlet (outer) tube diameter can be reduced from $130 \mathrm{~mm}$ to $40 \mathrm{~mm}$ with fixed outlet (inner) tube diameter $20 \mathrm{~mm}$. Heat transfer rate can be enhanced by reducing the outlet tube diameter for a fixed inlet tube diameter but pressure drop also increased. The heat transfer rate and pressure drop are related to both the mass flow rate (Reynolds number) and size of the GHE, it is good choice to install small size (inlet diameter $40 \mathrm{~mm}$ and outlet diameter $20 \mathrm{~mm}$ for example) double tube vertical GHE and operate in laminar flow condition. This reduced size GHE and laminar flow operation will save overall cost of installation and high pumping work as well as save selection of high capacity pump and operating cost. Long time operation suggests the possibility of installation of multiple double tube vertical GHE placing at $2.0 \mathrm{~m}$ lateral distance.

Since the heat transfer is dominated by ground around GHE, copper tube and stainless steel showed same almost same effect on heat transfer rate though the thermal conductivity of copper is 28 times higher than stainless steel. Furthermore HDPE is usually used in installation of GHE, the present study suggests that in double tube GHE, inlet (outer) tube with HDPE and outlet (inner) tube with PVC is more effective than HDPE tubes use both in inlet and outlet.

\section{Acknowledgements}

This work was sponsored by the project on "Renewable energy-heat utilization technology \& development project" of New Energy and Industrial Technology Development Organization (NEDO), Japan.

\section{References}

[1] J. E. Bose, M. D Smith, and J. D. Spitler, "Advances in ground source heat pump systems-An international overview," Proceedings of the Seventh International Energy Agency Heat Pump Conference, 2002, Beijing, China, pp. 313-324.

[2] I. Sarbu, and C. Sebarchievici, "General review of ground source heat pump systems for heating and cooling of buildings," Energy and Buildings, 2014, vol. 70, pp. 441-454.

[3] H. Esen, M. Inalli, "Thermal response of ground for different depths on vertical ground source heat pump system in Elazig, Turkey," Journal of the Energy Institute, 2009, vol. 82 (2), pp. 95-101.

[4] S. P. Kavanaugh, and K. Rafferty, "Ground-source heat pumps, design of geothermal systems for commercial and institutional buildings," 1997, Atlanta: ASHRAE.

[5] D. Banks, "An introduction to thermo geology: ground source heating and cooling," 2008, Wiley-Blackwell.

[6] H. Yang, P. Cui, and Z. Fang, "Vertical-borehole ground-coupled heat pumps: a review of models and systems," Applied Energy, 2010, vol. 87 (1), pp. 16-27.

[7] M. Khan, "Modeling, simulation and optimization of ground source heat pump systems," M. S. Thesis, Oklahoma State University, 2004, USA.

[8] V. Khalajzadeh, G. Heidarinejad, and J. Srebric, "Parameters optimization of a vertical ground heat exchanger based on response surface methodology" Energy and Buildings., 2011, vol. 43 (6), pp. 1288-1294.

[9] S. Sanaye, and B. Niroomand, "Thermal-economic modeling and optimization of vertical ground-coupled heat pump," Energy Conversion and Management, 2009, vol. 50 (4), pp. 1136-1147.

[10] S. Huang, Z. Ma, and F. Wang, "A multi-objective design optimization strategy for vertical ground heat exchangers," Energy and Buildings, 2015, vol. 87, pp. 233-242.

[11] J. E. Bose, J. D. Parker, and F. C. McQuiston, "Design/Data manual for closed-loop ground coupled heat pump systems," Atlanta, ASHRAE, 1985.

[12] C. Zhang, S. Hu, Y. Liu, and Q. Wang, "Optimal design of borehole heat exchangers based on hourly load simulation," Energy, 2016, vol. 116, pp. 1180-1190.

[13] W. Zhang, H. Yang, L. Lu, and Z. Fang, "The heat transfer analysis and optimal design on borehole ground heat exchangers," Energy Procedia, 2014, vol. 61, pp. 385 - 388.

[14] X. Y. Li, T. Y. Li, D. Q. Qu, and J. W. Yu, "A new solution for thermal interference of vertical U-tube ground heat exchanger for cold area in China," Geothermics, 2017, vol. 65, pp. 72-80.

[15] G. Florides, E. Theofanous, I. Iosif-Stylianou, S. Tassou, P. Christodoulides, Z. Zomeni, E. Tsiolakis, S. Kalogirou, V. Messaritis, P. Pouloupatis, and G. Panayiotou, "Modeling and assessment of the efficiency of horizontal and vertical ground heat exchangers," Energy, 2013, vol. 58, pp. 655-663.

[16] Jalaluddin, and A. Miyara, "Thermal performance and pressure drop of spiral-tube ground heat exchangers for ground-source heat pump," Applied Thermal Engineering, 2015, vol. 90, pp. 630-637.

[17] Jalaluddin, A. Miyara, K. Tsubaki, S. Inoue, and K. Yoshida, "Experimental study of several types of ground heat exchanger using a steel pile foundation," 2011, Renewable Energy, vol. 36, pp. 764-771.

[18] Jalaluddin, and A. Miyara, Thermal performance investigation of several types of vertical ground heat exchangers with different operation mode, Applied Thermal Engineering, 2012, vol. 33-34, pp. 167-174. 
[19] JSME Data Book: Heat Transfer, fifth ed. The Japan Society of Mechanical Engineers, 2009, (in Japanese).

[20] A. Bejan, and A. D. Kraus, "Heat transfer handbook," John Wiley \& Sons, Inc., New Jersey, 2003.

[21] ANSYS $^{\circledR}$ Academic Research, Release 17.2.

[22] ANSYS ${ }^{\circledR}$ Academic Research, Release 17.2, Help System, Fluent Theory Guide, ANSYS, Inc.
[23] ANSYS $^{\circledR}$ Academic Research, Release 17.2, Help System, Fluent User's Guide, ANSYS, Inc.

[24] H. N. Pollack, S. J. Hurter, and J. R. Johnson, "Heat flow from the earth's interior: analysis of the global data set," Rev. Geophys, 1993, vol. 31, pp. 267-280. 